\title{
Acute Heart Failure in the Emergency Department: Respiratory Rate as a Risk Predictor
}

\author{
EFTYCHIOS SINIORAKIS ${ }^{1}$, SPYRIDON ARVANITAKIS ${ }^{1}$, CHRISTINA TSITSIMPIKOU $^{2}$, \\ KONSTANTINOS TSAROUHAS ${ }^{3}$, PANAGIOTIS TZEVELEKOS ${ }^{1}$, STAMATIA PANTA $^{1}$, FOTINI AIVALIOTI ${ }^{1}$, \\ CONSTANTINOS ZAMPELIS ${ }^{1}$, FILIPPOS TRIPOSKIADIS ${ }^{3}$ and SOTIRIA LIMBERI ${ }^{1}$ \\ ${ }^{1}$ Cardiology Department, Sotiria Chest Diseases General Hospital, Athens, Greece; \\ ${ }^{2}$ General Chemical State Laboratory of Greece, Athens, Greece; \\ ${ }^{3}$ Department of Cardiology, University Hospital of Larissa, Larissa, Greece
}

\begin{abstract}
Background/Aim: Several risk scores can stratify patients with acute heart failure $(A H F)$ at the Emergency Department (ED). Registration of vital signs, such as blood pressure $(B P)$, heart rate $(H R)$ and respiratory rate $(R R)$ upon admission is mandatory. Nevertheless, measurement of $R R$ remains neglected worldwide. Patients and Methods: The predictive value of RR in classifying patients with AHF was investigated by processing several vital signs recorded in the ED. Results: HR and RR individually did not discriminate patients according to hospitalization length, Intensive Care Unit (ICU) admittance, mechanical respiratory support or death. The derivative indices, $H R: R R$ and Respiratory Efficacy Index (REFI) (=RR×100/SatO $\left.\mathrm{O}_{2}\right)$, differentiated study patients regarding hospitalization length. Receiver operating characteristic curves predicting mortality and ICU admission for REFI and HR:RR revealed high accuracy, sensitivity and specificity for cut-off values of REFI $>27$ and $H R: R R \geq 4$. Conclusion: The $R R$ and its derivative indices are easily accessible vital signs monitored at the ED which merit 'revitalization'.
\end{abstract}

The vast majority of patients (80-90\%) presenting at the Emergency Department (ED) with acute heart failure (AHF) are hospitalized $(1,2)$. Half of them are in mild condition, rendering their hospitalization unessential and financially unwarranted (3-5). On the other hand, patients misclassified as being at low-risk and discharged directly from the ED are

This article is freely accessible online.

Correspondence to: Dr. Konstantinos Tsarouhas, MD, M.Sc., Ph.D., ERT, Department of Cardiology, University Hospital of Larissa, Mezourlo Larissa 41110, Greece. E-mail: ktsarouhas14@yahoo.gr

Key Words: Heart failure, heart rate, respiratory rate, Emergency Department. prone to early complications, with a 7-day mortality reaching $4 \%(6,7)$. Several risk scores have been suggested in order to stratify patients with $\mathrm{AHF}$ at the $\operatorname{ED}(8,9)$. Registration of vital signs upon admission, such as blood pressure (BP), heart rate (HR), body temperature, and respiratory rate (RR) is mandatory $(10,11)$. Nevertheless, measurement of RR remains neglected worldwide $(12,13)$. In this study, the predictive value of $\mathrm{RR}$ in classifying patients with AHF hospitalized through the ED was investigated in order to emphasize on the need for monitoring RR at the ED.

\section{Patients and Methods}

The registration charts and ED-monitored parameters of all patients presenting with AHF at the ED of Sotiria Chest Diseases General Hospital, Athens, Greece during 2014 were reviewed. The study protocol conformed to the ethical guidelines of the 1975 Declaration of Helsinki and to Title 45, U.S. Code of Federal Regulations, Part 46, Protection of Human Subjects (effective December 13, 2001) as reflected in a priori approval by the Institution's Human Research Committee (approval number AM 3/2013).

Among 985 consecutive patients who presented with AHF at the ED, RR was recorded at the ED in only $262(26.5 \%)$ and 100 were hospitalized, constituting the study population. Therefore, selection bias was minimized.

For each patient, demographics, comorbidities, triggering factors, vital signs, arterial oxygen saturation $\left(\mathrm{SatO}_{2}\right)$ at the $\mathrm{ED}$, inotropic support and length of hospitalization were collected. The novel derivative indices, heart rate to respiratory rate (HR:RR) and respiratory efficacy index $\left(\mathrm{REFI}=\mathrm{RR} \times 100 / \mathrm{SatO}_{2}\right)$, were also introduced using the values measured at the $\mathrm{ED}$. Need for intubation, admittance to the intensive care unit (ICU) and death constituted the study endpoints. Length of hospitalization was also one of the clinical outcome measures and a nominal variable was created for statistical purposes: $\leq 6$ days, 7-10 days, $\geq 10$ days.

Statistical analysis. The SPSS 12.0 package (SPSS Inc, Chicago, IL, USA) was used. Normally distributed continuous variables were expressed as the mean \pm standard deviation and categorical variables as percentages. The independent $t$-test and the Mann-Whitney $U$-test were applied to compare means and medians. Pearson and Spearman 
in vivo $32: 921-925(2018)$

Table I. Demographical characteristics and medical condition of the study population.

\begin{tabular}{|c|c|c|c|c|}
\hline & Total population of the study & Patients in ICU & Patients intubated & Deaths \\
\hline Number of patients & 100 & 30 & 17 & 6 \\
\hline Mean age \pm SD (years) & $80.6 \pm 6.59$ & $82.0 \pm 5.28$ & $84.5 \pm 3.99 * * *$ & $80.4 \pm 6.65$ \\
\hline Men, $\mathrm{n}$ & 49 & 11 & 7 & 3 \\
\hline Women, $\mathrm{n}$ & 51 & 19 & 10 & 3 \\
\hline \multicolumn{5}{|l|}{ Comorbidities, $\mathrm{n}$} \\
\hline Atrial fibrillation & 63 & 15 & 11 & 4 \\
\hline CAD & 71 & 22 & 12 & 3 \\
\hline Valvulopathy & 32 & 12 & 7 & 2 \\
\hline COPD & 61 & 21 & $14 *$ & 4 \\
\hline Renal Injury & 30 & 12 & 8 & $4^{*}$ \\
\hline Diabetes & 82 & 24 & 14 & 6 \\
\hline Malignancy & 35 & 11 & 7 & 3 \\
\hline Nursing home & 14 & 5 & 3 & $3 * *$ \\
\hline Dementia & 47 & 16 & 11 & 4 \\
\hline Chronic hypertension & 31 & 3 & 2 & 0 \\
\hline \multicolumn{5}{|l|}{ Precipitating factors, $\mathrm{n}$} \\
\hline Acute coronary syndrome & 12 & $11^{*}$ & 2 & 0 \\
\hline Hypertensive crisis & 18 & 0 & 0 & 0 \\
\hline Non-compliance with previous treatment & 10 & 1 & 0 & 1 \\
\hline Respiratory infection & 19 & $13^{*}$ & $10 *$ & 5 \\
\hline Tachyarrythmias & 27 & 4 & 4 & 0 \\
\hline Other/unknown & 14 & 1 & 1 & 0 \\
\hline \multicolumn{5}{|l|}{ Vital signs, mean $\pm \mathrm{SD}$} \\
\hline $\mathrm{SBP}(\mathrm{mmHg})$ & $124 \pm 45.6$ & $103 \pm 36.1 * *$ & $89.7 \pm 27.2 * * *$ & $91.7 \pm 17.2^{* *}$ \\
\hline DBP $(\mathrm{mmHg})$ & $71.6 \pm 20.0$ & $60.3 \pm 13.2 * * *$ & $55.9 \pm 11.2 * * *$ & $61.7 \pm 7.53$ \\
\hline HR (beats/min) & $105 \pm 27.5$ & $101 \pm 25.6$ & $114 \pm 23.6$ & $99.8 \pm 24.6$ \\
\hline $\mathrm{RR}$ (breaths/min) & $25.9 \pm 6.03$ & $30.6 \pm 6.28 * * *$ & $34.4 \pm 3.39 * * *$ & $37.2 \pm 1.33 * * *$ \\
\hline Body temperature $\left({ }^{\circ} \mathrm{C}\right)$ & $36.9 \pm 0.836$ & $37.4 \pm 1.24 * *$ & $37.7 \pm 1.42 *$ & $38.2 \pm 1.44$ \\
\hline Saturation $\mathrm{O}_{2}(\%)$ & $89.4 \pm 3.43$ & $86.7 \pm 4.05 * * *$ & $83.8 \pm 2.10 * * *$ & $84.0 \pm 3.63 * * *$ \\
\hline REFI & $29.2 \pm 7.76$ & $35.6 \pm 8.48 *$ & $41.0 \pm 4.58^{*}$ & $44.3 \pm 3.21 *$ \\
\hline HR:RR & $4.18 \pm 1.24$ & $3.34 \pm 0.70 * * *$ & $3.34 \pm 0.70^{*}$ & $2.68 \pm 0.64 * *$ \\
\hline In-hospital inotropic support & 12 & $11 * * *$ & $9 * * *$ & $3^{* * *}$ \\
\hline Previous hospitalization & 37 & $16^{*}$ & $13 * * *$ & $6 * * *$ \\
\hline LOS (days) & $8.35 \pm 3.98$ & $11.4 \pm 4.03^{*}$ & $14.2 \pm 1.98 * *$ & $12.7 \pm 4.27 * *$ \\
\hline
\end{tabular}

ICU: Intensive Care Unit, CAD: coronary artery disease, COPD: chronic obstructive pulmonary disease, SBP: systolic blood pressure, DBP: diastolic blood pressure, HR: heart rate, RR: respiratory rate, REFI: respiratory efficacy index, LOS: length of stay in hospital, SD: standard deviation. Significantly different at $* p<0.05, * * p<0.01$, and $* * * p<0.001$ compared with the total population of the study.

correlations were also investigated. Differences between categorical variables were assessed by the chi-square test. Multiple logistic regression analysis with backward selection investigated associations between various variables. Several measurable parameters acting as possible confounders (age, sex, HR, BP, $\mathrm{SatO}_{2}, \mathrm{RR}$ and length of hospitalization) were included in the initial variable set. Percentile analysis and contingency tables were prepared and Kaplan-Meier survival curves were developed to study the relationship of HR:RR and REFI with the number of deaths recorded and ICU admission. The prognostic ability of HR:RR and REFI on ICU admission was also evaluated by receiver operating characteristic (ROC) curves. $p$-Values less than 0.05 were considered statistically significant.

\section{Results}

Table I summarizes the demographical characteristics and the medical evaluation of the study population in total and by subgroup for the study endpoints (need for intubation, admittance in the ICU and death). All vital signs presented were recorded at the ED upon hospital admission.

RR was increased by $18 \%(p=0.03)$ in patients admitted to ICU compared to the total population of the study and was $33 \%(p=0.02)$ higher in patients treated with mechanical respiratory support due to severe AHF that caused respiratory insufficiency compared to the general study population, while the increase of RR in patients who finally died was even higher, reaching $44 \%$ ( $p=0.04)$.

Percentile analysis and multiple logistic regression analysis with backward selection showed that HR and RR individually were not able to discriminate patients according to the AHF severity indices (ICU admittance, mechanical respiratory support, death). 
A high discriminatory ability was detected for the introduced HR:RR and REFI indices. Using the most relevant median $=$ values revealed by percentile analysis, $H R: R R=4$ and $\mathrm{REFI}=27$ were selected as cut-off points and were used to dichotomize the data in multiple logistic regression analyses. Both HR:RR and REFI differentiated study patients regarding the duration of their hospitalization ( $p=0.007$ and $p=0.001$ respectively, Figure 1A and B). However, multiple logistic regression analysis revealed that only REFI as a dichotomous variable was associated with the length of hospitalization (beta $=0.361,95 \% \mathrm{CI}=0.285-0.438, p=0.01$ ) among the various parameters tested (age, sex, HR, BP, $\mathrm{SatO}_{2}, \mathrm{RR}$ ).

Furthermore, Kaplan-Meier curves showed longer hospitalization in patients who died and presented a HR:RR $<4$ (median $=10$ days, range $=8.3-11.7$ days) compared to patients with HR:RR $\geq 4$ (median=6 days, range=5.6-6.4 days, $p<0.001$ ). Similarly, Kaplan-Meier curves showed higher hospitalization length for patients who died and presented a REFI $>27$ (median=14 days, range=13.1-14.9 days) compared to those with REFI $\leq 27$ (median=9 days, range=7.5-10.5, $p=0.007$ ). Kaplan-Meier curves with endpoint admission to ICU revealed longer hospitalization for patients who presented to the ED with REFI $>27$ (median=11.1 days, range=10.1-11.90 days), compared to those with REFI $\leq 27$ (median=7.2 days, range $=5.5$ 8.5 days, $p=0.007$ ) (Figure 2). Use of the HR:RR index did not lead to statistically significant results for patients admitted to ICU regarding the duration of hospitalization $(p=0.095)$.

There was a strong bivariate correlation between ICU hospitalization and HR:RR $<4$ (83.3\% of patients, $p<0.001)$. The same applied to REFI $>27$ ( $73.3 \%$ of patients, $p=0.002)$.

The prognostic value of REFI measured at the ED in identifying patients needing ICU admission was evaluated by ROC curves (Figure 3). At REFI=27, accuracy of $79.4 \%$, sensitivity of $73.3 \%$ and specificity $60 \% \quad(p<0.01$ respectively) were found. Similarly ROC curve analysis proved the prognostic value of HR:RR measured at the ED in identifying patients needing ICU admission and showed that for HR:RR=3.98, accuracy, sensitivity and specificity were $81.1 \%, 83.3 \%$ and $70.0 \%$, respectively $(p<0.001)$. The cut-off values for HR:RR and REFI were similar to those obtained from percentile analysis regarding the prediction of ICU admission. In multiple logistic regression analysis, however, only REFI was associated with ICU admission (beta $=0.512,95 \% \mathrm{CI}=0.487-0.567, p<0.015$ ).

In addition, a strong bivariate correlation was noted between recorded deaths and HR:RR<4 (100\% of patients, $p=0.009)$. The same applied to REFI $>27$ ( $100 \%$ of patients, $p=0.012)$.

ROC curve analysis for the predictive ability of REFI with a cut-off of 38 regarding mortality gave accuracy, sensitivity and specificity of $96.7 \%, 89.4 \%$ and $100 \% \quad(p<0.001)$, respectively. ROC curve analysis for the predictive ability of HR:RR index with a cut-off value of 3.85 for mortality gave accuracy, sensitivity and specificity of $77.7 \%, 87.8 \%$ and
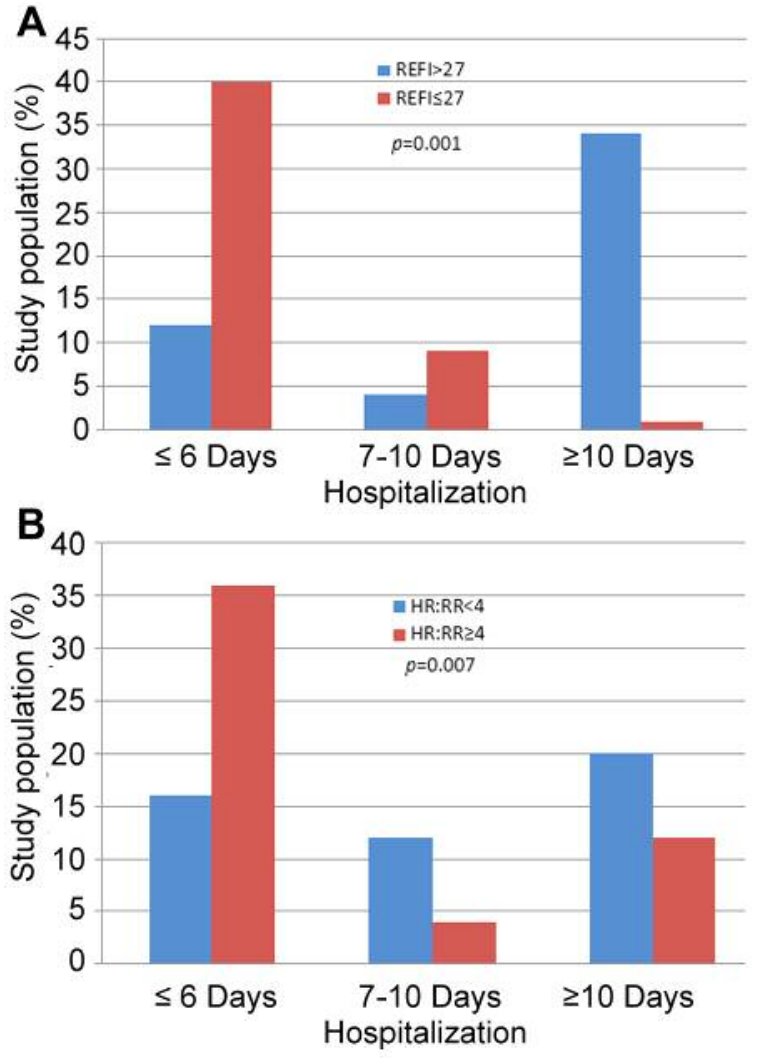

Figure 1. Length of hospitalization based on respiratory efficacy index $(R E F I)(A)$ and heart rate to respiratory rate (HR:RR) index (B).

$70.0 \%$, respectively $(p=0.001)$. It is worth noting that the HR:RR cut-off value of 3.85 was statistically equal to the median of 4 from the percentile analysis.

In the subgroup of patients with atrial fibrillation (AF) in the present study, a statistically significantly higher mean HR (13) was recorded $(110 \pm 29.1$ beats $/ \mathrm{min}, p=0.01)$. The AF patients of our study also had lower systolic BP $(118 \pm 40.6 \mathrm{mmHg}$, $p=0.05$ ), but all other vital signs, such as RR, diastolic BP, $\mathrm{SatO}_{2}$, along with the length of hospitalization, were statistically similar to those of the rest of the study population. In addition, patients with AF did not differ from the rest of the study population regarding the study endpoints, namely the need for intubation, admittance to ICU and death. Removing patients with AF from the analysis did not qualitatively alter the results.

\section{Discussion}

In the present study, medical practitioners who first treated dyspneic patients with $\mathrm{AHF}$ were reluctant to register $\mathrm{RR}$ at the ED, similar to the worldwide recorded percentage of $30 \%$, mainly due to the lack of awareness among the ED staff (14). The average RR in our study population is similar to those 
A

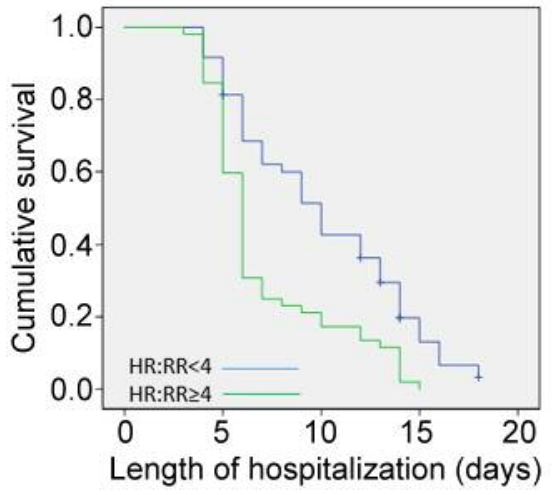

B

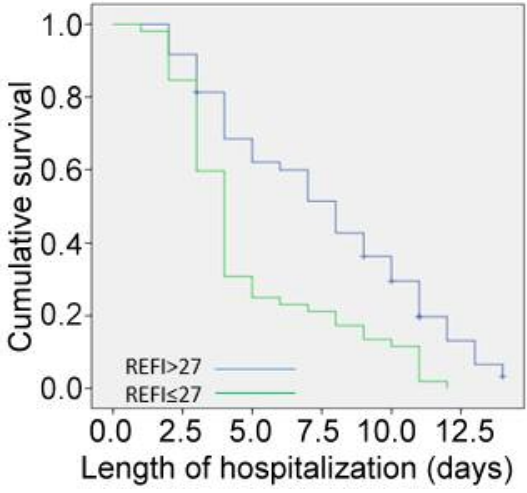

C

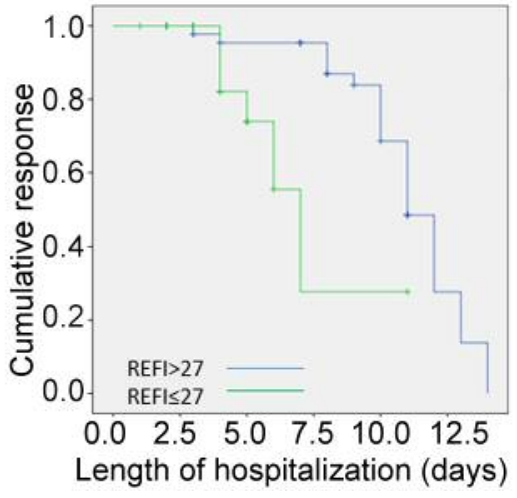

Figure 2. Kaplan-Meier curve for length of hospitalization in patients who died according to the heart rate to respiratory rate (HR:RR) index (A), and respiratory efficacy index (REFI) (B), and for length of hospitalization in patients admitted to Intensive Care Unit according to REFI (C).

reported for large AHF cohorts (15-17). Similarly the incidence of death in the present study was comparable to previous reports (18). Increased RR values in this study population were also related to intubation incidence, admission to ICU and in-hospital death. Similarly, the presence of tachypnea in the ED was correlated in a recent study with the need for mechanical ventilation, cardiac arrest incidence and early failure of outpatient treatment following discharge from the ED (19). Even in children, impaired lung function can lead to heart failure (16). Risk scores evaluating the severity of AHF in the ED, usually co-examine tachypnea with tachycardia and hypoxemia, in a triad reflecting the grade of cardio-respiratory distress $(6,20)$. In the presence of all three, the risk for 1- and 7-day mortality rises to $10 \%$ and $17 \%$, respectively (10). $\mathrm{HR}, \mathrm{RR}$ and $\mathrm{SatO}_{2}$ were combined in this study to develop the HR:RR and REFI indices, which were shown to be efficient in the prognostic discrimination regarding patient predisposition to ICU admission, length of hospitalization and final outcome, as expected from clinical practice experience, even in the $\mathrm{AF}$ subgroup (21). The HR of the patients with AF of our study was also higher than the mean HR of a recently published analysis on a large cohort of patients with AF presenting HF, probably due to the acute stress of our patients (13). Recently, new approaches regarding the breathlessness of patients with AHF at rest needing hospitalization have been developed; interestingly the belief that shortness of breath at admission is closely linked to mortality is challenged, while breathlessness at slight exertion might be more significant in risk both for in-hospital mortality and even up to 180 days post-hospital presentation (18). As breathlessness in patients with AHF is again in the spotlight, viewing it from a different angle with the new indices suggested in the current study, which combine different aspects of sympathetic activation, such as HR and RR, might further contribute to the early characterization of patients with AHF.

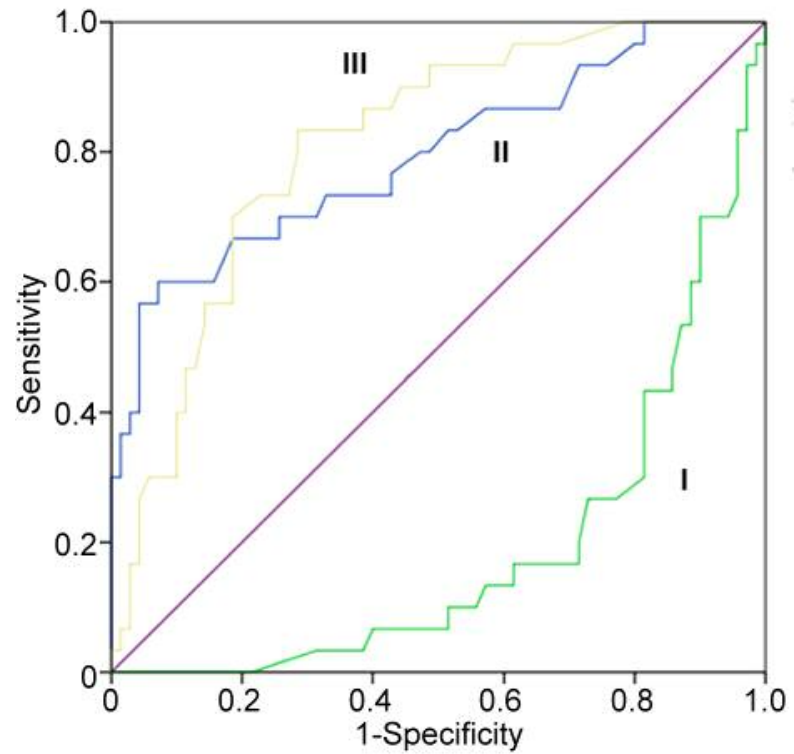

Figure 3. Receiver operating characteristic curves for the prognostic ability of the respiratory rate to heart rate (RR:HR) index (I), the respiratory efficacy index (REFI) (II) and the heart rate to respiratory rate (HR:RR) (III) index in predicting Intensive Care Unit admission of patients with acute heart failure.

In conclusion, despite the relatively small number of patients and the fact that the study was conducted only at one hospital, our findings might assist the risk stratification of AHF in the ED, contributing to a more cost-effective treatment of patients with AHF without the need for support from analytical hospital departments. At the same time, further medical complications as a result of downgrading the risk of patients with decompensated AHF risk 
in the ED could also be avoided. The RR and its derivative indices are easily accessible vital signs, which merit 'revitalization'.

\section{Conflicts of Interest}

The Authors report no conflicts of interest in regard to this study.

\section{References}

1 Peacock WF, Braunwald E, Abraham W, Albert N, Burnett J, Christenson R, Collins S, Diercks D, Fonarow G, Hollander J, Kellerman A, Gheorghiade M, Kirk D, Levy P, Maisel A, Massie BM, O'Connor C, Pang P, Shah M, Sopko G, Stevenson L, Storrow A and Teerlink J: National heart, lung, and blood institute working group on Emergency Department management of acute heart failure: Research challenges and opportunities. J Am Coll Cardiol 56(5): 343-351, 2010.

2 Collins SP and Storrow AB: Moving toward comprehensive acute heart failure risk assessment in the Emergency Department: The importance of self-care and shared decision making. JACC Heart Fail 1(4): 273-280, 2013.

3 Collins SP, Lindsell CJ, Jenkins CA, Harrell FE, Fermann GJ, Miller KF, Roll SN, Sperling MI, Maron DJ, Naftilan AJ, McPherson JA, Weintraub NL, Sawyer DB and Storrow AB: Risk stratification in acute heart failure: Rationale and design of the stratify and decide studies. Am Heart J 164(6): 825-834, 2012.

4 Collins SP, Pang PS, Fonarow GC, Yancy CW, Bonow RO and Gheorghiade M: Is hospital admission for heart failure really necessary?: The role of the Emergency Department and observation unit in preventing hospitalization and rehospitalization. J Am Coll Cardiol 61(2): 121-126, 2013.

5 Farmakis D, Parissis J, Karavidas A, Karvounis C, Triposkiadis F, Filippatos G, Lekakis $J$ and Collaborators: In-hospital management of acute heart failure: Practical recommendations and future perspectives. Int J Cardiol 201: 231-236, 2015.

6 Lee DS, Stitt A, Austin PC, Stukel TA, Schull MJ, Chong A, Newton GE, Lee JS and Tu JV: Prediction of heart failure mortality in emergent care: A cohort study. Ann Intern Med 156(11): 767-775, 2012.

7 Ho EC, Schull MJ and Lee DS: The challenge of heart failure discharge from the emergency department. Curr Heart Fail Rep 9(3): 252-259, 2012.

8 Abraham WT, Fonarow GC, Albert NM, Stough WG, Gheorghiade M, Greenberg BH, O'Connor CM, Sun JL, Yancy $\mathrm{CW}$, Young JB, Investigators $\mathrm{O}-\mathrm{H}$ and Coordinators: Predictors of in-hospital mortality in patients hospitalized for heart failure: Insights from the organized program to initiate lifesaving treatment in hospitalized patients with heart failure (OptimizeHF). J Am Coll Cardiol 52(5): 347-356, 2008.

9 Fonarow GC, Adams KF Jr., Abraham WT, Yancy CW, Boscardin WJ, Adhere Scientific Advisory Committee SG and Investigators: Risk stratification for in-hospital mortality in acutely decompensated heart failure: Classification and regression tree analysis. JAMA 293(5): 572-580, 2005.

10 Van Spall HG, Atzema C, Schull MJ, Newton GE, Mak S, Chong A, Tu JV, Stukel TA and Lee DS: Prediction of emergent heart failure death by semi-quantitative triage risk stratification. PLoS One 6(8): e23065, 2011.
11 Pascual-Figal DA, Caballero L, Sanchez-Mas J and Lax A: Prognostic markers for acute heart failure. Expert Opin Med Diagn 7(4): 379-392, 2013.

12 Cretikos MA, Bellomo R, Hillman K, Chen J, Finfer S and Flabouris A: Respiratory rate: The neglected vital sign. Med J Aust 188(11): 657-659, 2008.

13 Hortmann $\mathrm{M}$, Nickel $\mathrm{CH}$, Bingisser $\mathrm{R}$ and Christ $\mathrm{M}$ : Significance of the respiratory rate in emergency medicine. Dtsch Arztebl Int 112(10): 173, 2015.

14 di Martino P, Leoli F, Cinotti F, Virga A, Gatta L, Kleefield S and Melandri R: Improving vital sign documentation at triage: An Emergency Department quality improvement project. J Patient Saf 7(1): 26-29, 2011.

15 Metra M, Cotter G, El-Khorazaty J, Davison BA, Milo O, Carubelli V, Bourge RC, Cleland JG, Jondeau G, Krum H, O'Connor CM, Parker JD, Torre-Amione G, van Veldhuisen DJ, Rainisio M, Kobrin I, McMurray JJ and Teerlink JR: Acute heart failure in the elderly: Differences in clinical characteristics, outcomes, and prognostic factors in the Veritas study. J Card Fail 21(3): 179-188, 2015.

16 Shiraishi Y, Kohsaka S, Harada K, Sakai T, Takagi A, Miyamoto T, Iida K, Tanimoto S, Fukuda K, Nagao K, Sato N, Takayama M and Scientific Committee of Tokyo CCUN: Time interval from symptom onset to hospital care in patients with acute heart failure: A report from the Tokyo Cardiac Care Unit Network Emergency Medical Service Database. PLoS One 10(11): e0142017, 2015.

17 O'Connor CM, Starling RC, Hernandez AF, Armstrong PW, Dickstein K, Hasselblad V, Heizer GM, Komajda M, Massie BM, McMurray JJ, Nieminen MS, Reist CJ, Rouleau JL, Swedberg K, Adams KF Jr., Anker SD, Atar D, Battler A, Botero R, Bohidar NR, Butler J, Clausell N, Corbalan R, Costanzo MR, Dahlstrom U, Deckelbaum LI, Diaz R, Dunlap ME, Ezekowitz JA, Feldman D, Felker GM, Fonarow GC, Gennevois D, Gottlieb SS, Hill JA, Hollander JE, Howlett JG, Hudson MP, Kociol RD, Krum H, Laucevicius A, Levy WC, Mendez GF, Metra M, Mittal S, Oh BH, Pereira NL, Ponikowski P, Tang WH, Tanomsup S, Teerlink JR, Triposkiadis F, Troughton RW, Voors AA, Whellan DJ, Zannad F and Califf RM: Effect of nesiritide in patients with acute decompensated heart failure. N Engl J Med 365(1): 32-43, 2011.

18 Shoaib A, Waleed M, Khan S, Raza A, Zuhair M, Kassianides X, Djahit A, Goode K, Wong K, Rigby A, Clark A and Cleland $\mathrm{J}$ : Breathlessness at rest is not the dominant presentation of patients admitted with heart failure. Eur J Heart Fail 16(12): 1283-1291, 2014.

19 Rialp Cervera G, del Castillo Blanco A, Perez Aizcorreta O, Parra Morais L and SEMICYUC G-Io: Noninvasive mechanical ventilation in chronic obstructive pulmonary disease and in acute cardiogenic pulmonary edema. Med Intensiva 38(2): 111-121, 2014.

20 Park JJ, Choi DJ, Yoon CH, Oh IY, Lee JH, Ahn S, Yoo BS, Kang SM, Kim JJ, Baek SH, Cho MC, Jeon ES, Chae SC, Ryu $\mathrm{KH}$, Oh BH and Kor HFR: The prognostic value of arterial blood gas analysis in high-risk acute heart failure patients: An analysis of the Korean Heart Failure (KorHF) registry. Eur J Heart Fail 17(6): 601-611, 2015.

21 Kakouros NS and Kakouros SN: Clinical assessment in acute heart failure. Hellenic J Cardiol 56(4): 285-301, 2015.

Received March 24, 2018

Revised April 21, 2018

Accepted April 26, 2018 